\title{
A yeast strain associated to Anopheles mosquitoes produces a toxin able to kill malaria parasites
}

\author{
Matteo Valzano ${ }^{1}$, Valentina Cecarini', Alessia Cappelli ${ }^{1}$, Aida Capone ${ }^{1}$, Jovana Bozic ${ }^{1}$, Massimiliano Cuccioloni ${ }^{1}$,
} Sara Epis ${ }^{2}$, Dezemona Petrelli ${ }^{1}$, Mauro Angeletti ${ }^{1}$, Anna Maria Eleuteri ${ }^{1}$, Guido Favia ${ }^{1}$ and Irene Ricci ${ }^{1 *}$

\begin{abstract}
Background: Malaria control strategies are focusing on new approaches, such as the symbiotic control, which consists in the use of microbial symbionts to prevent parasite development in the mosquito gut and to block the transmission of the infection to humans. Several microbes, bacteria and fungi, have been proposed for malaria or other mosquito-borne diseases control strategies. Among these, the yeast Wickerhamomyces anomalus has been recently isolated from the gut of Anopheles mosquitoes, where it releases a natural antimicrobial toxin. Interestingly, many environmental strains of $W$. anomalus exert a wide anti-bacterial/fungal activity and some of these 'killer'yeasts are already used in industrial applications as food and feed bio-preservation agents. Since a few studies showed that W. anomalus killer strains have antimicrobial effects also against protozoan parasites, the possible anti-plasmodial activity of the yeast was investigated.
\end{abstract}

Methods: A yeast killer toxin (KT), purified through combined chromatographic techniques from a W. anomalus strain isolated from the malaria vector Anopheles stephensi, was tested as an effector molecule to target the sporogonic stages of the rodent malaria parasite Plasmodium berghei, in vitro. Giemsa staining was used to detect morphological damages in zygotes/ookinetes after treatment with the KT. Furthermore, the possible mechanism of action of the KT was investigated pre-incubating the protein with castanospermine, an inhibitor of $\beta$-glucanase activity.

Results: A strong anti-plasmodial effect was observed when the $P$. berghei sporogonic stages were treated with $\mathrm{KT}$, obtaining an inhibition percentage up to around $90 \%$. Microscopy analysis revealed several ookinete alterations at morphological and structural level, suggesting the direct implication of the KT-enzymatic activity. Moreover, evidences of the reduction of KT activity upon treatment with castanospermine propose a $\beta$-glucanase-mediated activity.

Conclusion: The results showed the in vitro killing efficacy of a protein produced by a mosquito strain of $W$. anomalus against malaria parasites. Further studies are required to test the KT activity against the sporogonic stages in vivo, nevertheless this work opens new perspectives for the possible use of killer strains in innovative strategies to impede the development of the malaria parasite in mosquito vectors by the means of microbial symbionts.

Keywords: Wickerhamomyces anomalus, Plasmodium berghei, Anopheles stephensi, Malaria, Symbiotic control, Killer toxin

\footnotetext{
*Correspondence: irene.ricci@unicam.it

1 School of Biosciences and Veterinary Medicine, University of Camerino,

62032 Camerino, Italy

Full list of author information is available at the end of the article
} 


\section{Background}

Malaria is one of the most alarming infectious diseases threatening millions people, mostly in sub-Saharan regions [1, 2]. It is caused by Plasmodium protozoan parasites and transmitted by Anopheles mosquitoes. Even though several traditional remedies are in use, the disease continues to represent a heavy health burden in endemic countries. In absence of effective vaccines, public health programmes have focused their resources on the use of insecticides to reduce the number of vector populations, and/or drugs to kill directly the pathogens [3].

Malaria control programmes involving chemical and pharmacological treatments are not always sustainable due to several factors, such as economic costs and logistic aspects. In addition, both vectors and parasites have enhanced resistance against many commonly used pesticides and medicines. Confirmed resistance of 125 mosquito species lead the Malaria Eradication Research Agenda to state that novel control strategies are urgently requested for malaria suppression [4]. In this frame, a new tool called "Symbiotic Control" (SC) has been recently proposed. The SC is a multifaceted approach that exploits symbiotic microorganisms to control insect pests reducing their vector capabilities [5, 6]. This strategy implies the identification of suitable microbes able to spread among the vector populations. Several microbes have been proposed for malaria-SC, including the bacteria Asaia, Wolbachia, Pantoea agglomerans, Elizabethkingia meningoseptica and the fungi Metarhizium robertsii and Wickerhamomyces anomalus [7-12].

The yeast $W$. anomalus has been recently isolated from different mosquito species [13] and its intimate association with its host has been well characterized in the Asian malaria vector Anopheles stephensi, where the yeast localizes to gut and gonads, suggesting specific biological roles in these anatomical districts [12]. Similar to various environmental strains used as bio-preservation agents for their anti-bacterial/fungal activities in food industry, the W. anomalus strain isolated from An. stephensi secretes an antimicrobial KT, which might exert an antiseptic function in the mosquito [14, 15]. Previous results showed the effective antimicrobial activity of the $\mathrm{KT}$, produced by $W$. anomalus strain of mosquito against other targeted yeasts [14]. The $W$. anomalus potency to be stimulated for KT production was demonstrated, whose releases in the mosquito midgut and gonads showing long-lasting features [14]. Consequently, the possible KT anti-plasmodial effect against parasite developmental stages was investigated, taking place in mosquito gut. In the present study, a strong in vitro antimicrobial activity of the KT secreted by the W. anomalus strain isolated from Anopheles stephensi against the sporogonic stages of the malaria rodent parasite Plasmodium berghei was determined and a killing mechanism of action based on a $\beta$-glucanase enzymatic activity was proposed.

\section{Methods}

Yeast strains

Three W. anomalus strains were used: (1) WaF17.12 isolated from An. stephensi [12], (2) WaATCC 96603 a KT-producer reference strain and (3) WaUM3 a WaKTnon-producing and, furthermore, WaKT-susceptible strain $[16,17]$. These yeasts were grown in YPD liquid medium (20 g/l peptone, $20 \mathrm{~g} / \mathrm{l}$ glucose, $10 \mathrm{~g} / \mathrm{l}$ yeast extract) buffered at $\mathrm{pH} 4.5$ with $0.1 \mathrm{M}$ citric acid and $0.2 \mathrm{M}$ potassium phosphate dibasic and incubated at $26{ }^{\circ} \mathrm{C}$ for $36 \mathrm{~h}$ at $70 \mathrm{rpm}$ to stimulate the production of KTs $[18,19]$.

\section{Purification of yeast KTs}

The yeast cultures obtained after $36 \mathrm{~h}$ incubation were centrifuged at $3000 \mathrm{rpm}$ for $10 \mathrm{~min}$ to remove cells. The supernatants were filtered using $0.22 \mu \mathrm{m}$ nitrocellulose membranes, and concentrated $50 \times$ using an Amicon system equipped with Millipore Ultracell ultrafiltration disk (MWCO: $10 \mathrm{kDa}$ ). The samples were further concentrated using Pierce Concentrators centrifugal ultrafiltration tubes with a MWCO of $9 \mathrm{kDa}$ (Thermo Fisher Scientific Inc). Resulting solutions were analysed by anion-exchange chromatography on a FPLC AKTA Basic device equipped with a HiTrap DEAE FF column (GE Healthcare) using a linear gradient of buffer A $(0.1 \mathrm{M}$ citric acid and $\left.0.2 \mathrm{M} \mathrm{K}_{2} \mathrm{HPO}_{4}, \mathrm{pH} 4.5\right)$ and buffer $\mathrm{B}(0.1 \mathrm{M}$ citric acid and $0.2 \mathrm{M} \mathrm{K}_{2} \mathrm{HPO}_{4}, \mathrm{pH} 4.5$ ), flow rate $5 \mathrm{ml} /$ min.

Retained and non-retained fractions for each strain were collected from different runs, quantified for protein content according to the Bradford's method [20] and tested for the presence of killing activity against the susceptible strain WaUM3, as described by Cappelli [14]. Prior to anti-P. berghei activity assay, the non-retained fractions of WaF17.12 and WaATCC 96603 showing the KT activity, and the non-retained fraction of WaUM3 (negative control), were buffer-exchanged with an $\mathrm{Hi}$ Trap desalting column to PBS $1 \times\left(10 \mathrm{mM} \mathrm{Na}_{2} \mathrm{HPO}_{4}\right.$, $2.7 \mathrm{mM} \mathrm{KCl}, 138 \mathrm{mM} \mathrm{NaCl}, \mathrm{pH}$ 7.4) to prevent possible interference, like $\mathrm{pH}$-incompatibility, with the parasite development.

\section{Ethics statement}

$\mathrm{BALB} / \mathrm{c}$ mice were reared in the animal facilities of the University of Camerino (Italy). Experimental animal rearing and handling were fully in agreement with the Italian Directive 116 of 10/27/92 on the "use and protection of laboratory animals", and in compliance with the European regulation (86/609) of 11/24/86 (license no. 
$125 / 94 \mathrm{~A}$, issued by the Italian Ministry of Health). The experimentation was approved by the Ethical Committee of University of Camerino.

\section{Mice infection and Plasmodium berghei sporogonic stages cultures}

Five-week-old BALB/c mice were infected with a recombinant $P$. berghei strain (PbCTRPp.GFP) from a cryopreserved stock, as previously described by Vlachou et al. [21]. This transgenic parasite expresses the Green Fluorescent Protein (GFP) during ookinete development under the control of the ctrp promoter, whereas no signal is exhibited in the asexual blood stages and gametocytes. After 4 days, mice parasitaemia and haematocrit were evaluated using Giemsa staining and Neubauer's chamber, respectively. Mice with a parasitaemia in the range $5-10 \%$ were selected as donors, and $10^{7}$ infected red blood cells (IRBC) were inoculated into healthy mice, previously treated with phenylhydrazine to induce reticulocytosis [22]. After further 4 days, exflagellation centres were counted as indicators of parasite infectivity [23], using an optical microscope with a $40 \times$ objective (Carl Zeiss Axio Observer.Z1, Milan, Italy). To induce exflagellation, $5 \mu \mathrm{l}$ of infected blood were blended with $120 \mu \mathrm{l}$ of incomplete ookinete medium (16.4 g/l RPMI1640 containing $25 \mathrm{mM} \mathrm{HEPES/L-glutamine,} 2 \%$ $\mathrm{NaHCO}_{3}, 0.05 \%$ hypoxanthine, $100 \mu \mathrm{M}$ xanthurenic acid, $\mathrm{pH} 8$ ) and incubated $20 \mathrm{~min}$ at $22{ }^{\circ} \mathrm{C}$ as reported by Ghosh et al. [24]. After the check of exflagellation centers, gametocytaemic blood was collected by cardiac puncture.

Plasmodium berghei sporogonic stages were obtained, in vitro, culturing $20 \mu \mathrm{l}$ of infected blood with $180 \mu \mathrm{l}$ of complete ookinete medium in a 96-wells microtitre plates. Complete medium was prepared supplementing the above-mentioned incomplete medium with $20 \%$ heat inactivated fetal bovine serum (Invitrogen), $50 \mathrm{U} / \mathrm{ml}$ penicillin and $50 \mu \mathrm{g} / \mathrm{ml}$ streptomycin (Invitrogen). Ookinetes developed after about $24 \mathrm{~h}$ at $19^{\circ} \mathrm{C}$.

\section{In vitro WaKTs anti-plasmodial activity}

The fractions containing the KTs obtained by chromatographic analysis of the extracts, from WaF17.12, WaATCC 96603 (positive control) and WaUM3 (negative control) were tested against $P$. berghei sporogonic stage cultures prepared as described above. Four concentrations $(25,60,75,100 \mu \mathrm{g} / \mathrm{ml})$ of KTs from both WaF17.12 and WaATCC 96603 were tested; whereas for WaUM3, the purification product was tested at the highest concentration possible to evaluate interference due to buffer solution. Concurrently, in each control well, PBS $1 \times \mathrm{pH} 7.4$ (without KT) was added to ookinete complete medium and gametocytaemic blood. After $24 \mathrm{~h}$ incubation at $19{ }^{\circ} \mathrm{C}$, the KTs anti-plasmodial activity was estimated comparing the number of fluorescent $P$. berghei sporogonic stages in both control and sample wells using a fluorescence microscope and $40 \times$ objective (Carl Zeiss Axio Observer.Z1, Milan, Italy). The assays were performed in triplicate using 96-wells microtitre plates and the results were reported as the averages of inhibition percentages of parasite development.

The $\mathrm{LC}_{50}$ (KTs concentration at which $50 \%$ of the parasite population is killed) was evaluated after $24 \mathrm{~h}$. This value was determined by nonlinear regression analysis plotting the number of sporogonic stages versus $\log [\mathrm{KT}]$ with GraphPad Prism 5 software as described by Savoia et al. [25].

\section{Statistical analysis}

Five runs of parasite cultures were obtained during the experimentation and the results of each run were reproducible. All the experiments against Plasmodium sporogonic stages were repeated in triplicate. The data obtained from parasite counts were analysed with GraphPad Prism 5 software and statistical analysis was carried out by One Way ANOVA followed by Bonferroni's Multiple Comparison Tests. Statistical significance is expressed as a $p$ value $<0.05$.

\section{Morphological analysis of Plasmodium berghei sporogonic stages using Giemsa staining}

Control and KT-treated (KTs concentration $100 \mu \mathrm{g} / \mathrm{ml}$ ) $P$. berghei sporogonic stages slides were investigated for possible damages induced by KT-activity on the zygote and/or ookinete morphologies. Briefly, $5 \mu \mathrm{l}$ of parasite cultures were smeared onto a glass slide, fixed by methanol for $15 \mathrm{~min}$ at room temperature and stained for 45 min with $10 \%$ Giemsa solution (Sigma-Aldrich) in PBS $1 \times \mathrm{pH} 7.4$. After this incubation period the samples were analysed using a microscope and $100 \times$ objective (Carl Zeiss Axio Observer.Z1, Milan, Italy).

\section{Castanospermine assay}

Purified KTs $(100 \mu \mathrm{g} / \mathrm{ml})$ from both WaF17.12 and WaATCC 96603 were pre-incubated with $25 \mu \mathrm{M}$ of castanospermine (Sigma-Aldrich), a $\beta$-glucanase inhibitor, for $1 \mathrm{~h}$ at $25{ }^{\circ} \mathrm{C}$ under static conditions [26] and, then, added to the $P$. berghei cultures, in triplicates. The inhibitory effect of the indolizine alkaloid on the antimicrobial activity of KTs was evaluated on P. berghei sporogonic stage cultures after $24 \mathrm{~h}$ incubation at $19{ }^{\circ} \mathrm{C}$ and it was indicated as the average of three replicates. Upon castanospermine treatment, the number of parasites was compared to controls. 


\section{Results}

\section{Purification of KTs}

The KTs from $W$. anomalus strains were purified to test their ability to inhibit the development of $P$. berghei sporogonic stages. The purification process started with the production of the $\mathrm{KT}$ in yeast culture medium, and proceeded with a series of concentrations and chromatographic steps.

Three different strains of $W$. anomalus growing in conditions stimulating the production of toxin [14] were used: (1) the KT-producer WaF17.12 isolated from $A n$. stephensi mosquitoes; (2) the KT-producer WaATCC 96603 (positive control), and (3) the non KT-producer WaUM3 (negative control). Anion-exchange chromatography analysis has revealed the presence of two major peaks in each yeast strains analysed: non-retained and retained fractions (Fig. 1). Due to similar chromatographic profiles, a killing activity test was performed in order to discriminate effective $\mathrm{KT}$ presence in the fractions obtained from the three different strains. Killing activity assay on the susceptible WaUM3 strain, revealed $\mathrm{KT}$ presence only in the first eluted fraction of WaF17.12 and WaATCC 96603 strains (see Additional file 1).

Accordingly, these fractions were used against $P$. berghei sporogonic stages.

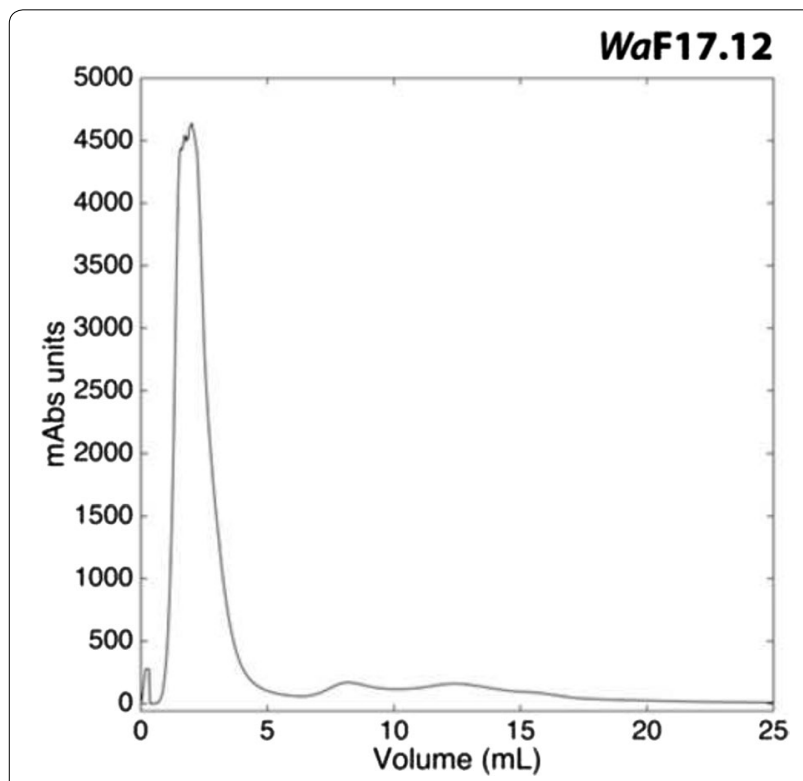

Fig. 1 Anion-exchange chromatography profile. Profile obtained through the anion-exchange chromatography (DEAE) performed on the concentrated supernatant of the strain WaF1712. The same elution profile was achieved also for the strains WaATCC 96603 (positive control) and WaUM3 (negative control)

\section{In vitro anti-plasmodial activity of WaKTs}

KTs purified from WaF17.12 and WaATCC 96603 supernatants were tested on $P$. berghei cultures. KT concentrations were compatible with those of killer peptides used against the promastigotes of Leishmania sp., in vitro conditions [25]. The KTs secreted by both $W$. anomalus F17.12 and W. anomalus ATCC 96603 showed antiplasmodial activity against the development of $P$. berghei sporogonic stages; whereas no effect was detected when the cultures were incubated with the purified supernatant of WaUM3. Indeed, the ookinetes treated with non-retained fraction of WaUM3 showed a comparable development with the control (see Additional file 2).

Notably, KTs activity showed a dose-depending trend. Treatment with $100 \mu \mathrm{g} / \mathrm{ml}$ of WaF17.12 and WaATCC $96603 \mathrm{KTs}$ induced the highest inhibition percentages of the sporogonic stages development (87.5 and $92.3 \%$, respectively) (Fig. 2). Inhibition percentages upon exposure to $25,60,75 \mu \mathrm{g} / \mathrm{ml}$ of $\mathrm{WaF} 17.12 \mathrm{KT}$ were approximately of 17, 43 and $66 \%$, whereas for WaATCC 96603 KT were about 16, 48 and $70 \%$ (Fig. 3). The values of $\mathrm{LC}_{50}$ were 61.3 and $64.6 \mu \mathrm{g} / \mathrm{ml}$ for WaATCC 96603 and WaF17.12, respectively, suggesting an equivalent activity of the two proteins.

\section{Investigation of morphological/structural alterations in treated parasites}

Upon GFP-parasites treatment with KTs, a lower fluorescence signal in the sporogonic stages was detected. Figure 4 shows a comparison between control and treated parasites from zygotes to ookinetes. Intracellular GFP leakage might result from KTs-induced alterations on the permeability of the parasites cell membrane. To better investigate $\mathrm{KT}$-induced morphological changes in $P$. berghei sporogonic stages, smears of parasites cultures were stained with $10 \%$ Giemsa. Morphologically, alterations of the post-zygotic stages were evidenced, whereas no particular differences were observed at the zygotes level (Fig. 5). In details, zygotes from both groups (controls and KTs-treated) appeared comparable in size with intensely colored cytoplasm while treated ones showed irregular borders and less defined cytoplasmic granules and crystalloid precursors (Fig. 5a, d). In control parasites, the ookinete development was characterized by a completed elongation process and the presence of a strong staining and well-defined crystalloid organelles surrounded with haemozoin (Fig. 5b, c). The morphological/structural alterations of the postzygotic stages of the KT-treated parasites included: (1) irregular cell-shape and jagged cell borders; (2) a feeble staining of cytoplasmic region; (3) the lack of crystalloid assembly and (4) less-defined cytoplasmic granules, (Fig. 5e, f). 


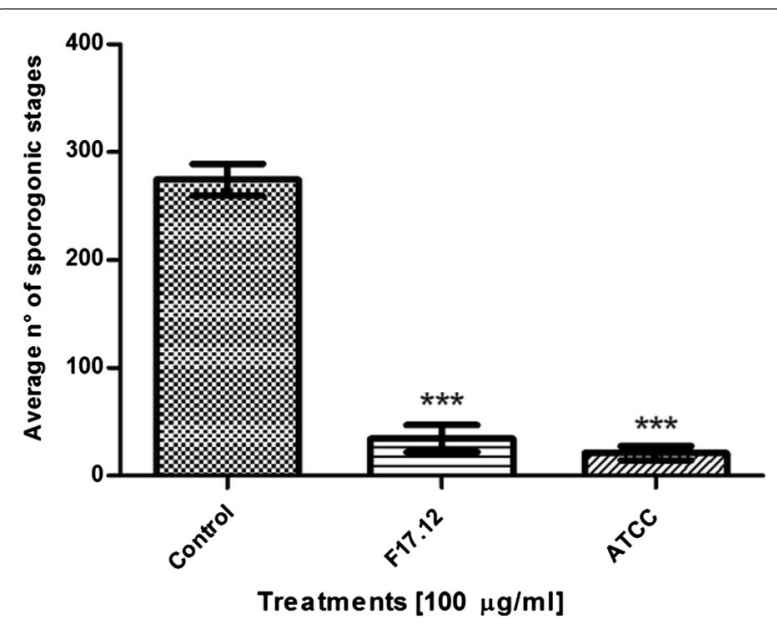

Fig. 2 In vitro anti-plasmodial activity of WaKTs against Plasmodium berghei sporogonic stages. The development of sporogonic stages showed inhibition rates of 87.5 and $92.3 \%$ when they were incubated with $100 \mu \mathrm{g} / \mathrm{ml}$ of WaF17.12 and WaATCC $96603 \mathrm{KTs}$, respectively, for $24 \mathrm{~h}$ at $19^{\circ} \mathrm{C}$. The histogram reports the average numbers of the sporogonic stages obtained from the cell count of three wells for each treatment and control $\left(\mathrm{LC}_{50}\right.$ values were 61.3 and $64.6 \mathrm{\mu g} / \mathrm{ml}$ for WaATCC 96603 and WaF17.12, respectively). The One Way ANOVA Bonferroni's Multiple Comparison tests were used to perform the statistical analysis. Statistical significance is expressed as a $p$ value. *** $p<0.001$

\section{Possible KT mechanism of action}

The main antimicrobial mechanism of W. anomalus involves the direct killing of sensitive microorganisms by releasing of KTs that recognize specific cell-wall receptors on target membranes [27]. One of the proposed mechanism of action of these proteins is based on their interference with the glucans determining a $\beta-1,3-$ glucanase activity [28].

To verify if the toxicity against the $P$. berghei sporogonic stages of KTs was mediated by $\beta$-glucanase activity, the KTs of both WaF17.12 and WaATCC 96603 were treated with castanospermine, a $\beta$-glucanase inhibitor [26]. Castanospermine-induced inhibition of KTs was evaluated after $24 \mathrm{~h}$ incubation compared to controls (Table 1). Castanospermine induced a reduction in the killer activity of both proteins (from 79.7 to $46.2 \%$ in the case of $W a \mathrm{~F} 17.12$ and from 88.5 to $49.5 \%$ in the case of WaATCC 96603) confirming the possible correlation between the enzymatic activity of KTs and the killer phenotype of the yeast.

\section{Discussion}

The yeast $W$. anomalus is known to display natural antimicrobial properties against a wide range of microbes, including the protozoan parasites Leishmania sp. and Acanthamoeba castellanii [15, 25, 29]. Herein, through a rapid chromatographic protocol [30], WaKT produced by WaF17.12 strain, isolated from the major Asian malaria mosquito vector, An. stephensi, was purified. Furthermore, the first evidence of this $\mathrm{KT}$ inhibition potential against $P$. berghei sporogonic stages in laboratory cultures was provided. The obtained outcomes report an undeniable parasite inhibition up to $90 \%$ compared to control samples. Alongside, although WaATCC 96603 reference strain has been already described for its robust

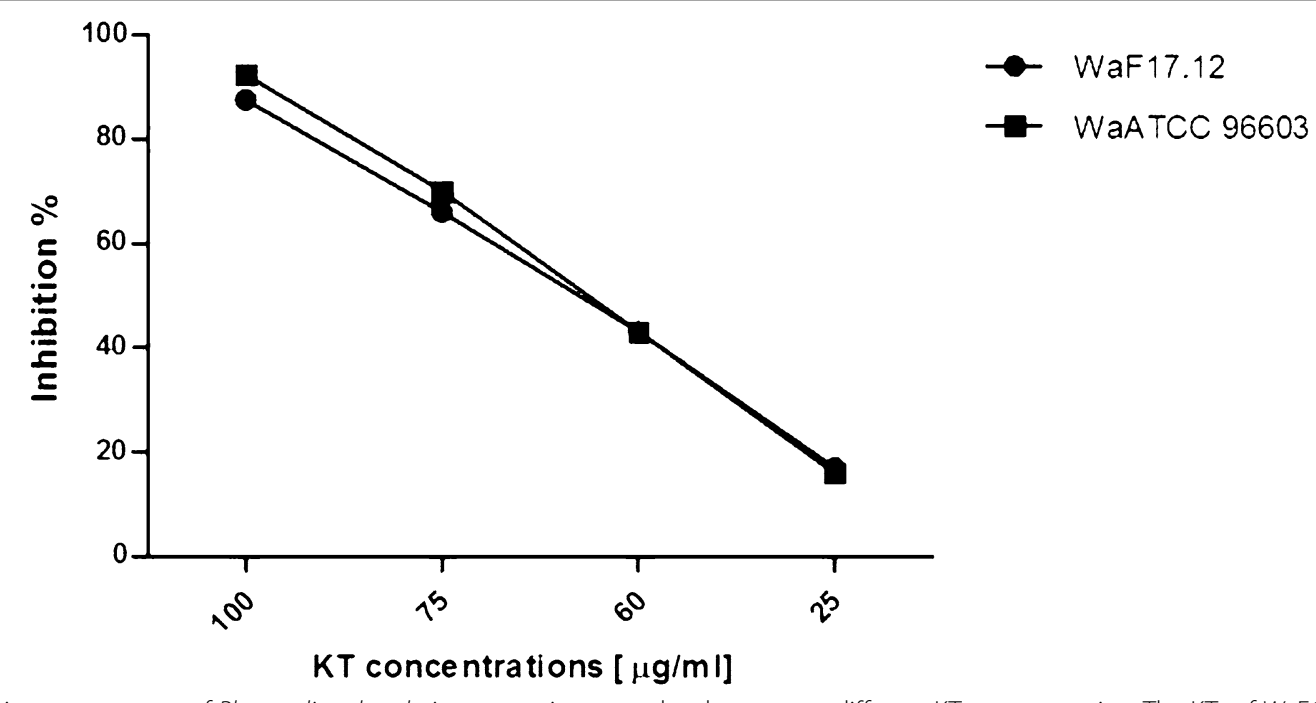

Fig. 3 Inhibition percentages of Plasmodium berghei sporogonic stages development at different KTs concentration. The KTs of WaF17.12 and WaATCC 96603 showed a dose-dependent activity at the tested concentrations of 100, 75, 60 and $25 \mu \mathrm{g} / \mathrm{ml}$. Inhibition percentages upon exposure to $25,60,75 \mu \mathrm{g} / \mathrm{ml}$ of WaF17.12 KT were approximately of $17,43,66 \%$, whereas for WaATCC $96603 \mathrm{KT}$ were about 16, 48 and $70 \%$ 

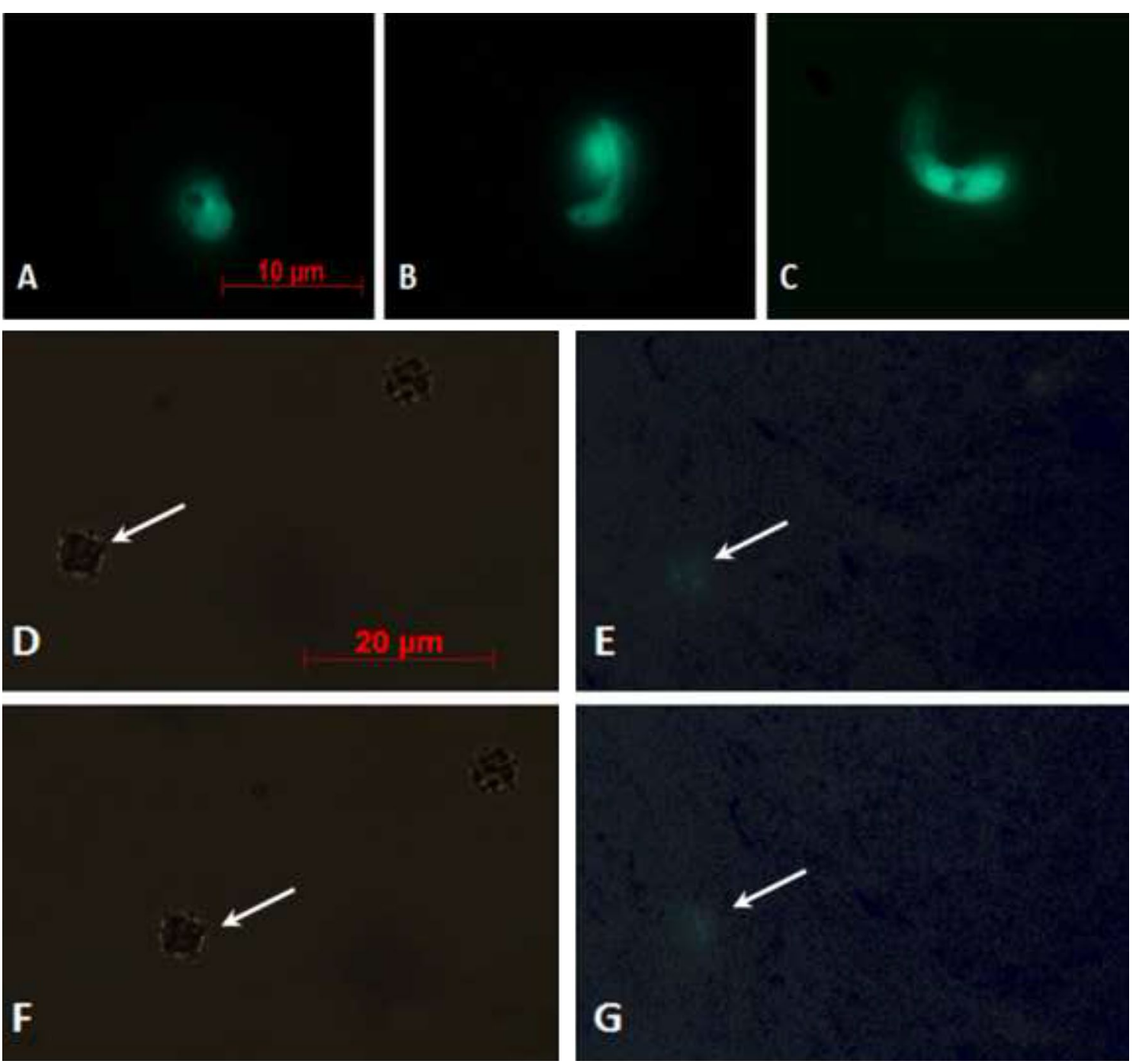

Fig. 4 Fluorescence microscopy evaluation of GFP-transfected parasites. Different stages of untreated parasite development are shown in a-c (a zygote; $\mathbf{b}$ elongated zygote; $\mathbf{c}$ mature ookinete). $\mathbf{e}$ and $\mathbf{g}$ show faint fluorescent signals into zygotes (indicated by white arrows) treated with WaF17.12-KT. In $\mathbf{d}$ and $\mathbf{f}$ phase-contrasts (the zygotes are indicated by white arrows) are shown. All the parasites were observed using a $\times 100$ objective. In a-c scale bar $10 \mu \mathrm{m}$ whereas in $\mathbf{d}-\mathbf{g}$ scale bar $20 \mu \mathrm{m}$

multi-target killing activity, its efficacy against $P$. berghei sporogonic stages was additionally estimated.

Subsequently, WaKT action mechanism was investigated through both enzymatic tests and Giemsa staining. Previous work demonstrated that KTs bind to cell-wall primary receptors, and then, move to secondary ones in the plasma membrane inducing the death of sensitive cells through DNA damages and apoptosis [25]. In particular, KT activity was associated with the hydrolysis of the $\beta$-glucans located in cell-wall membranes [28]. Notably, the $\beta-1,3$-glucans recognized by $\mathrm{KT}$, are known to be present not only in fungi but also in cell-wall of parasites, as reported in the protozoa Toxoplasma and Eimeria
[31], and they are implicated in the immune-protection against $P$. berghei infection in mice [32].

Moreover, it is reported that the bond between the $\mathrm{KT}$ and the membrane receptors causes the formation of transmembrane channels, determining the leak of intracellular materials [33]. A similar event was detected in amphotericin-treated promastigotes of Leishmania major suggesting a loss of intra-cellular material from apoptotic cells [25]. In this frame, a lower fluorescent signal in sporogonic stages treated with $\mathrm{KT}$ was observed respect to controls. The morphological and structural alterations observed in KT-treated parasites, using Giemsa staining, confirmed that WaF17.12 KT targets 

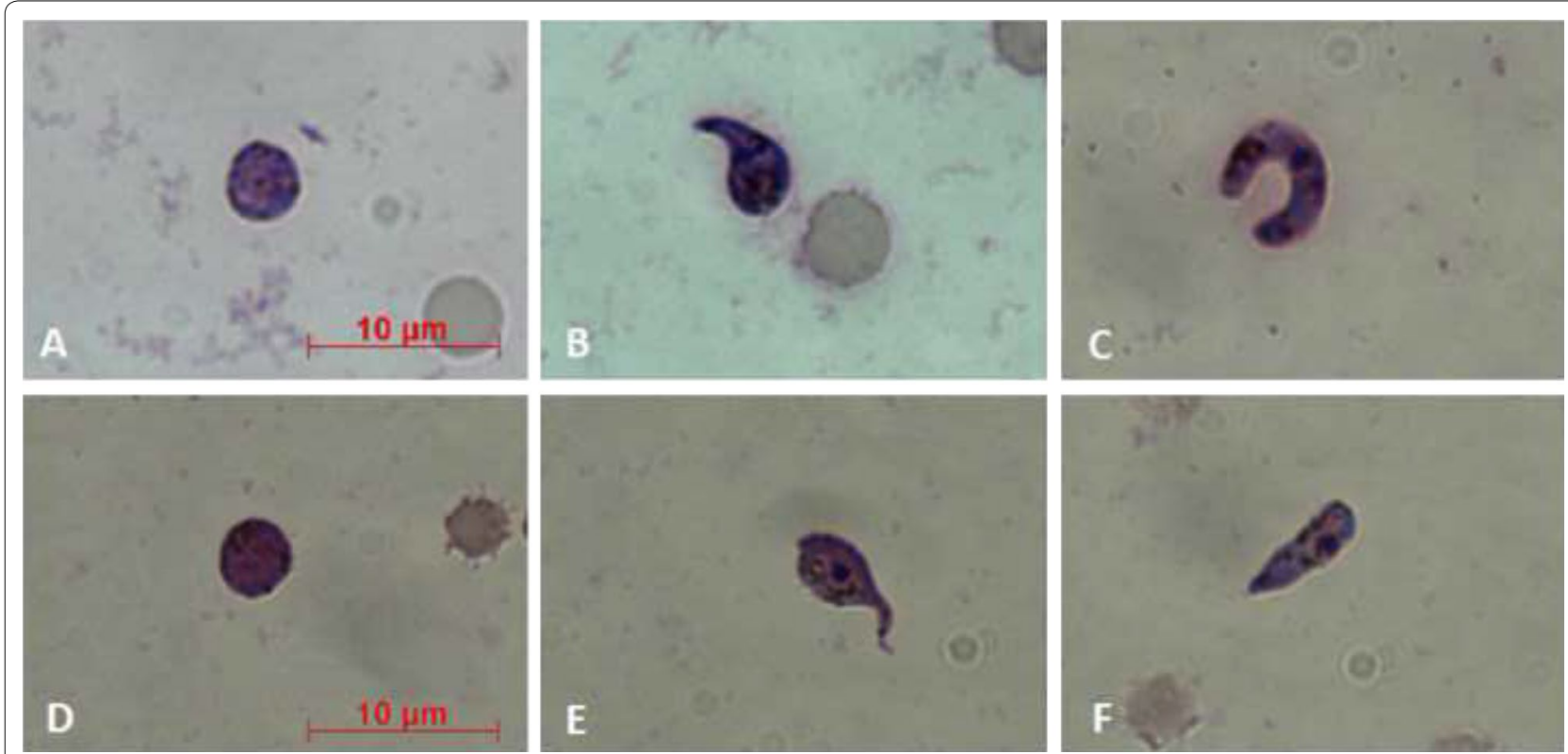

Fig. 5 Images of Plasmodium berghei cultures in Giemsa-stained smears. Parasites sporogonic stages, both controls (a-c) and treated with $100 \mu \mathrm{gg} /$ $\mathrm{ml}$ of WaF17.12 KT (d-f) were stained with Giemsa and analysed under light microscope ( $\times 100$ objective). See text for details. Scale bar $10 \mu \mathrm{m}$

Table 1 Effects of castanospermine on KTs activity against $P$. berghei

\begin{tabular}{|c|c|c|}
\hline $\begin{array}{l}\text { Pretreatment } \\
\beta \text {-Glucanase inhibitor }(25 \mu \mathrm{M})\end{array}$ & $\begin{array}{l}\text { Treatment } \\
\mathrm{KTs}(100 \mu \mathrm{g} / \mathrm{ml})\end{array}$ & $\begin{array}{l}\text { Average number of } \\
\text { sporogonic stages/well }\end{array}$ \\
\hline None & None & $305 \pm 22.7$ \\
\hline None & WaF17.12-KT & $62 \pm 11.5$ \\
\hline None & WaATCC 96603-KT & $35 \pm 4.6$ \\
\hline Castanospermine & WaF17.12-KT & $125 \pm 8.1$ \\
\hline Castanospermine & WaATCC 96603-KT & $151 \pm 4.5$ \\
\hline
\end{tabular}

the sporogonic stages of Plasmodium, interfering with the correct development of mature ookinetes.

Additionally, $\beta$-glucanase implication is also supported by the presence of the genes responsible for $\beta-1-3-$ glucanase synthesis (EXG1 and EXG2) in the genome of $W$. anomalus $[14,34,35]$ : their single or coupled silencing was in fact correlated with the lack of the yeast antimicrobial function; however, no direct relationship has been yet demonstrated between these genes and the KT activity [36].

For this reason, to evaluate the direct involvement of a $\beta$-glucanase activity of $\mathrm{KT}$ on malaria parasites, the $\beta$-glucanase inhibitor castanospermine was used. The inhibitory effect of castanospermine on the $\mathrm{WaKT}$ activity confirmed a $\beta$-glucanase-mediated mechanism of action, resulting consistent with data on Tetrapisispora phaffi [26]. However it is worth to underline that inhibition percentages in castanospermine-treated samples is still lower with respect untreated control: this is easily explained by the shortage of a suitable molecule concentration to saturate all the KT active sites.

Finally, an in-depth analysis of our results reinforced the idea that $\mathrm{KT}$, produced by the strain isolated from mosquitoes, interacts with specific receptors, the $\beta$-glucans, localized on the surface of $P$. berghei cells and strongly inhibits their development from gametocytes to ookinetes.

\section{Conclusion}

The overall outcome from this study paves the way for better understanding of the effect of WaKTs on the malaria parasite in the mosquito midgut, which coincides with the bottleneck in Plasmodium life cycle. Previously, Cappelli et al. showed that the $W$. anomalus strain associated to mosquito is able to produce a KT in An. stephensi [14]. Herein, it was demonstrated that this protein 
is strongly active against $P$. berghei, in vitro conditions. Future in vivo studies will focus on the action of KTs against rodent malaria parasites with the prospect to provide a natural tool for innovative malaria SC strategies.

\section{Additional files}

Additional file 1: Killing activity against WaUM3 strain

Additional file 2: Ookinetes development under WaUM3 non-retained fraction.

\section{Abbreviations}

SC: Symbiotic control; KT: Killer toxin; GFP: Green fluorescent protein; CTRP: Circumsporozoite and TRAP related protein; IRBC: Infected red blood cells; YPD: Yeast extract peptone dextrose; MWCO: Molecular weight cut off; FPLC: Fast protein liquid chromatography; DEAE FF: Diethylaminoethanol fast flow; PBS: Phosphate buffered saline; LC $_{50}$ : Lethal concentration 50.

\section{Authors' contributions}

MV designed and carried out the in vitro assays to evaluate the antiplasmodial activity of WaKTs; acquired the data and interpreted the results presented in the manuscript. VC performed the biochemical characterization of WaF17.12 KT; compiled the data and presented it in the form as it appears in the manuscript. AIC performed the experiments with MV and VC. AiC and $\mathrm{JB}$ cooperated in yeast cultivation and toxin purification. MC cooperated in the purification of the toxin. SE partially cooperated in practical. DP, MA, AME and GF advised on practical and reviewed the manuscript. IR conceived the experiments and wrote the paper. All authors read and approved the final manuscript.

\section{Author details}

${ }^{1}$ School of Biosciences and Veterinary Medicine, University of Camerino, 62032 Camerino, Italy. ${ }^{2}$ Department of Veterinary Sciences and Public Health, University of Milan, 20133 Milan, Italy.

\section{Acknowledgements}

The research was supported from the European Union Seventh Framework Programme (FP7/2007-2013_FP7/2007-2011) under Grant agreement No. 281222 to Irene Ricci.

\section{Competing interests}

The authors declare that they have no competing interests.

Received: 4 June 2015 Accepted: 17 December 2015

Published online: 11 January 2016

\section{References}

1. Murray CJ, Rosenfeld LC, Lim SS, Andrews KG, Foreman KJ, Haring D, et al. Global malaria mortality between 1980 and 2010: a systematic analysis. Lancet. 2012;379:413-31. doi:10.1016/S0140-6736(12)60034-8.

2. Wang S, Jacobs-Lorena M. Genetic approaches to interfere with malaria transmission by vector mosquitoes. Trends Biotechnol. 2013;31:185-93. doi:10.1016/j.tibtech.2013.01.001.

3. Riehle MA, Jacobs-Lorena M. Using bacteria to express and display antiparasite molecules in mosquitoes: current and future strategies. Insect Biochem Mol Biol. 2005;35:699-707.

4. malERA consultative group on basis science and enabling technologies. A research agenda for malaria eradication: basic science and enabling technologies. PLoS Med. 2011;8:e1000399.

5. Douglas AE. Symbiotic microorganisms: untapped resources for insect pest control. Trends Biotechnol. 2007;25:338-42.

6. Ricci I, Valzano M, Ulissi U, Epis S, Cappelli A, Favia G. Symbiotic control of mosquito borne disease. Pathog Glob Health. 2012;106:380-5. doi:10.1179/2047773212
7. Favia G, Ricci I, Damiani C, Raddadi N, Crotti E, Marzorati M, et al. Bacteria of the genus Asaia stably associate with Anopheles stephensi, an Asian malarial mosquito vector. Proc Natl Acad Sci USA. 2007;104:9047-51.

8. Wang J, Zhang Q, Huang Z, Liu Z. Directed evolution of a family 26 glycoside hydrolase: endo- $\beta-1,4-m a n n a n a s e$ from Pantoea agglomerans A021. J Biotechnol. 2013;167:350-6. doi:10.1016/j.jbiotec.2013.06.019.

9. Wang S, Ghosh AK, Bongio N, Stebbings KA, Lampe DJ, Jacobs-Lorena M. Fighting malaria with engineered symbiotic bacteria from vector mosquitoes. Proc Natl Acad Sci USA. 2012;109:12734-9.

10. Lindh JM, Borg-Karlson AK, Faye I. Transstadial and horizontal transfer of bacteria within a colony of Anopheles gambiae (Diptera: Culicidae) and oviposition response to bacteria-containing water. Acta Trop. 2008:107:242-50.

11. Fang W, Vega-Rodríguez J, Ghosh AK, Jacobs-Lorena M, Kang A, St Leger RJ. Development of transgenic fungi that kill human malaria parasites in mosquitoes. Science. 2011;331:1074-7.

12. Ricci I, Damiani C, Scuppa P, Mosca M, Crotti E, Rossi P, et al. The yeast Wickerhamomyces anomalus (Pichia anomala) inhabits the midgut and reproductive system of the Asian malaria vector Anopheles stephensi. Environ Microbiol. 2011;13:911-21. doi:10.1111/j.1462-2920.2010.02395.x.

13. Ricci I, Mosca M, Valzano M, Damiani C, Scuppa P, Rossi P, et al. Different mosquito species host Wickerhamomyces anomalus (Pichia anomala): perspectives on vector-borne diseases symbiotic control. Antonie Van Leeuwenhoek. 2011:99:43-50. doi:10.1007/s10482-010-9532-3.

14. Cappelli A, Ulissi U, Valzano M, Damiani C, Epis S, Gabrielli MG, et al. A Wickerhamomyces anomalus killer strain in the malaria vector Anopheles stephensi. PLoS One. 2014;9:e95988. doi:10.1371/journal.pone.0095988.

15. Walker GM. Pichia anomala: cell physiology and biotechnology relative to other yeasts. Antonie Van Leeuwenhoek. 2011;99:25-34.

16. Polonelli $\mathrm{L}$, Morace $\mathrm{G}$. Production and characterization of yeast killer toxin monoclonal antibodies. J Clin Microbiol. 1987;25:460-2.

17. Polonelli L, Séguy N, Conti S, Gerloni M, Bertolotti D, Cantelli C, et al. Monoclonal yeast killer toxin-like candidacidal anti-idiotypic antibodies. Clin Diagn Lab Immunol. 1997:4:142-6.

18. Guyard C, Séguy N, Cailliez JC, Drobeca H, Polonelli L, Dei-Cas E, et al. Characterization of a Williopsis saturnus var. mrakii high molecular weight secreted killer toxin with broad-spectrum antimicrobial activity. J Antimicrob Chemother. 2002;49:961-71.

19. Izgu F, Altinbay D, Acun T. Killer toxin of Pichia anomala NCYC 432; purification, characterization and its exo- $\beta$-1,3-glucanase activity. Enzyme Microb Technol. 2006;39:669-76

20. Bradford MM. A rapid and sensitive method for the quantitation of microgram quantities of protein utilizing the principle of protein-dye binding. Anal Biochem. 1976:72:248-54.

21. Vlachou D, Schlegelmilch T, Christophides GK, Kafatos FC. Functional genomic analysis of midgut epithelial responses in Anopheles during Plasmodium invasion. Curr Biol. 2005;15:1185-95.

22. Rodríguez LE, Urquiza M, Ocampo M, Curtidor H, Suárez J, García J, et al. Plasmodium vivax MSP-1 peptides have high specific binding activity to human reticulocytes. Vaccine. 2002;20:1331-9.

23. Ramakrishnan C, Delves MJ, Lal K, Blagborough AM, Butcher G, Baker KW, et al. Laboratory maintenance of rodent malaria parasites. Methods Mol Biol. 2013:923:51-72.

24. Ghosh AK, Dinglasan RR, Ikadai H, Jacobs-Lorena M. An improved method for the in vitro differentiation of Plasmodium falciparum gametocytes into ookinetes. Malar J. 2010;9:194. doi:10.1186/1475-2875-9-194.

25. Savoia D, Scutera S, Raimondo S, Conti S, Magliani W, Polonelli L. Activity of an engineered synthetic killer peptide on Leishmania major and Leishmania infantum promastigotes. Exp Parasitol. 2006;113:186-92.

26. Comitini F, Mannazzu I, Ciani M. Tetrapisispora phaffii killer toxin is a highly specific beta-glucanase that disrupts the integrity of the yeast cell wall. Microb Cell Fact. 2009:8:55. doi:10.1186/1475-2859-8-55.

27. Bevan EA, Makower M. The physiological basis of the killer character in yeast. In: Proceeding of the 11 th International Conference on Genetics, vol. 1. Oxford Pergamon Press, Oxford; 1963, pp. 53-8.

28. Magliani W, Conti S, Giovati L, Maffei DL, Polonelli L. Anti-beta-glucan-like immunoprotective candidacidal antiidiotypic antibodies. Front Biosci. 2008;13:6920-37

29. Fiori PL, Mattana A, Dessì D, Conti S, Magliani W, Polonelli L. In vitro acanthamoebicidal activity of a killer monoclonal antibody and a synthetic peptide. J Antimicrob Chemother. 2006:57:891-8. 
30. Guo FJ, Ma Y, Xu HM, Wang XH, Chi ZM. A novel killer toxin produced by the marine-derived yeast Wickerhamomyces anomalus YF07b. Antonie Van Leeuwenhoek. 2013;103:737-46.

31. Bushkin GG, Motari E, Magnelli P, Gubbels MJ, Dubey JP, Miska KB, et al. $\beta-1,3-$ glucan, which can be targeted by drugs, forms a trabecular scaffold in the oocyst walls of Toxoplasma and Eimeria. MBio. 2012;3:e00258-312. doi:10.1128/mBio.00258-12.

32. Maheshwari R, Siddiqui MU. Immunoprotection by beta-1,3 glucan antigen combination in Plasmodium berghei infection in mice. Indian J Med Res. 1989;89:396-403.

33. Buzdar MA, Chi Z, Wang Q, Hua MX, Chi ZM. Production, purification, and characterization of a novel killer toxin from Kluyveromyces siamensis against a pathogenic yeast in crab. Appl Microbiol Biotechnol. 2011;91:1571-9. doi:10.1007/s00253-011-3220-8.
34. Schneider J, Rupp O, Trost E, Jaenicke S, Passoth V, Goesmann A, et al. Genome sequence of Wickerhamomyces anomalus DSM 6766 reveals genetic basis of biotechnologically important antimicrobial activities. FEMS Yeast Res. 2012;12:382-6. doi:10.1111/j.1567-1364.2012.00791.x.

35. Muccilli S, Wemhoff S, Restuccia C, Meinhardt F. Exoglucanase-encoding genes from three Wickerhamomyces anomalus killer strains isolated from olive brine. Yeast. 2013;30:33-43. doi:10.1002/yea.2935.

36. Friel D, Pessoa NM, Vandenbol M, Jijakli MH. Separate and combined disruptions of two exo-beta-1,3-glucanase genes decrease the efficiency of Pichia anomala (strain K) biocontrol against Botrytis cinerea on apple. Mol Plant Microbe Interact. 2007;20:371-9.

\section{Submit your next manuscript to BioMed Central and we will help you at every step:}

- We accept pre-submission inquiries

- Our selector tool helps you to find the most relevant journal

- We provide round the clock customer support

- Convenient online submission

- Thorough peer review

- Inclusion in PubMed and all major indexing services

- Maximum visibility for your research

Submit your manuscript at www.biomedcentral.com/submit
() Biomed Central 